\title{
Novel xylanolytic triple domain enzyme targeted at feruloylated arabinoxylan degradation
}

Holck, Jesper; Brask, Jesper; Pilgaard, Bo; Krogh, Kristian B.R.M.; Meyer, Anne S.; Lange, Lene; Wilkens, Casper

\section{Published in:}

Enzyme and Microbial Technology

Link to article, DOI:

10.1016/j.enzmictec.2019.05.010

Publication date:

2019

Document Version

Peer reviewed version

Link back to DTU Orbit

Citation (APA):

Holck, J., Brask, J., Pilgaard, B., Krogh, K. B. R. M., Meyer, A. S., Lange, L., \& Wilkens, C. (2019). Novel xylanolytic triple domain enzyme targeted at feruloylated arabinoxylan degradation. Enzyme and Microbial Technology, 129, [109353]. https://doi.org/10.1016/j.enzmictec.2019.05.010

\section{General rights}

Copyright and moral rights for the publications made accessible in the public portal are retained by the authors and/or other copyright owners and it is a condition of accessing publications that users recognise and abide by the legal requirements associated with these rights.

- Users may download and print one copy of any publication from the public portal for the purpose of private study or research.

- You may not further distribute the material or use it for any profit-making activity or commercial gain

- You may freely distribute the URL identifying the publication in the public portal 


\section{Accepted Manuscript}

Title: Novel xylanolytic triple domain enzyme targeted at feruloylated arabinoxylan degradation

Authors: Jesper Holck, Demi T. Djajadi, Jesper Brask, Bo Pilgaard, Kristian B.R.M. Krogh, Anne S. Meyer, Lene Lange, Casper Wilkens

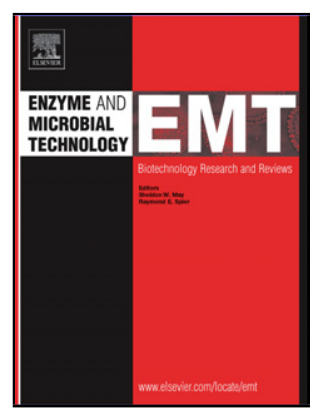

PII: S0141-0229(18)30637-9

DOI:

Reference: https://doi.org/10.1016/j.enzmictec.2019.05.010

To appear in: $\quad$ Enzyme and Microbial Technology

Received date: $\quad 29$ October 2018

Revised date: $\quad 2$ April 2019

Accepted date: $\quad 22$ May 2019

Please cite this article as: Holck J, Djajadi DT, Brask J, Pilgaard B, Krogh KBRM, Meyer AS, Lange L, Wilkens C, Novel xylanolytic triple domain enzyme targeted at feruloylated arabinoxylan degradation, Enzyme and Microbial Technology (2019), https://doi.org/10.1016/j.enzmictec.2019.05.010

This is a PDF file of an unedited manuscript that has been accepted for publication. As a service to our customers we are providing this early version of the manuscript. The manuscript will undergo copyediting, typesetting, and review of the resulting proof before it is published in its final form. Please note that during the production process errors may be discovered which could affect the content, and all legal disclaimers that apply to the journal pertain. 
Title: Novel xylanolytic triple domain enzyme targeted at feruloylated arabinoxylan degradation

Authors: Jesper Holck ${ }^{1}$, Demi T. Djajadi ${ }^{2}$, Jesper Brask ${ }^{3}$, Bo Pilgaard ${ }^{1}$, Kristian B. R. M. Krogh ${ }^{3}$, Anne S. Meyer ${ }^{1}$, Lene Lange ${ }^{4}$ and Casper Wilkens ${ }^{1 *}$

\section{Affiliations:}

${ }^{1}$ Enzyme Technology, Section for Protein Chemistry and Enzyme Technology, Department of Biotechnology and Biomedicine, Technical University of Denmark, Søltofts Plads, Building 224, DK-2800 Kgs. Lyngby, Denmark

${ }^{2}$ Center for Bioprocess Engineering, Department of Chemical and Biochemical Engineering, Technical University of Denmark, Søltofts Plads, Building 229, DK-2800 Kgs. Lyngby, Denmark ${ }^{3}$ Novozymes A/S, Krogshøjvej 36, DK-2880 Bagsværd, Denmark

${ }^{4}$ LLa-Bioeconomy, Research \& Advisory, Karensgade 5, DK-2500 Valby, Denmark

*Corresponding author: Casper Wilkens, Enzyme Technology, Section for Protein Chemistry and Enzyme Technology, Department of Biotechnology and Biomedicine, Technical University of Denmark, Søltofts Plads, Building 224, DK-2800 Kgs. Lyngby, Denmark, E-mail cwil@dtu.dk

\section{Highlights}

- The three domains of CE1-GH62-GH10 act in synergy to degrade wheat arabinoxylan

- CE1-GH62-GH10 and a mix of the catalytic domains display comparable activity levels

- The three domains all unfolds at $71.0 \pm 0.05^{\circ} \mathrm{C}$ when linked together

- $\mathrm{CE} 1$ and GH62 displayed lower thermostability than when linked together with GH10 


\begin{abstract}
A three catalytic domain multi-enzyme; a CE1 ferulic acid esterase, a GH62 $\alpha$-L-arabinofuranosidase and a GH10 $\beta$-D-1,4-xylanase was identified in a metagenome obtained from wastewater treatment sludge. The capability of the CE1-GH62-GH10 multi-enzyme to degrade arabinoxylan was investigated to examine the hypothesis that CE1-GH62-GH10 would degrade arabinoxylan more efficiently than the corresponding equimolar mix of the individual enzymes.
\end{abstract}

CE1-GH62-GH10 efficiently catalyzed the production of xylopyranose, xylobiose, xylotriose, arabinofuranose and ferulic acid (FA) when incubated with insoluble wheat arabinoxylan (WAX-I) $\left(k_{\mathrm{cat}}=20.8 \pm 2.6 \mathrm{~s}^{-1}\right)$. Surprisingly, in an equimolar mix of the individual enzymes a similar $k_{\mathrm{cat}}$ towards WAX-I was observed $\left(k_{\mathrm{cat}}=17.3 \pm 3.8 \mathrm{~s}^{-1}\right)$. Similarly, when assayed on complex plant biomass the activity was comparable between CE1-GH62-GH10 and an equimolar mix of the individual enzymes. This suggests that from a hydrolytic point of view a CE1-GH62-GH10 multienzyme is not an advantage. Determination of the melting temperatures for CE1-GH62-GH10 (71.0 $\left.\pm 0.05{ }^{\circ} \mathrm{C}\right)$ and $\mathrm{CE} 1(69.9 \pm 0.02)$, GH62 $(65.7 \pm 0.06)$ and $\mathrm{GH} 10\left(71 \pm 0.05{ }^{\circ} \mathrm{C}\right)$ indicates that $\mathrm{CE} 1$ and GH62 are less stable as single domain enzymes. This conclusion was corroborated by the findings that CE1 lost $\sim 50 \%$ activity within $2 \mathrm{~h}$, while GH62 retained $\sim 50 \%$ activity after $24 \mathrm{~h}$, whereas CE1GH62-GH10 and GH10 retained $\sim 50 \%$ activity for $72 \mathrm{~h}$.

GH62-GH10, when appended to each other, displayed a higher specificity constant $\left(k_{\mathrm{cat}} / K_{\mathrm{m}}=0.3 \mathrm{~s}^{-1}\right.$ $\left.\mathrm{mg}^{-1} \mathrm{ml}\right)$ than the individual GH10 $\left(k_{\mathrm{cat}} / K_{\mathrm{m}}=0.12 \mathrm{~s}^{-1} \pm 0.02 \mathrm{mg}^{-1} \mathrm{ml}\right)$ indicating a synergistic action between the two. Surprisingly, CE1-GH62, displayed a 2-fold lower $k_{\text {cat }}$ towards WAX-I than GH62, which might be due to the presence of a putative carbohydrate binding module appended to CE1 at the N-terminal. Both CE1 and CE1-GH62 released insignificant amounts of FA from WAX-I, but FA was released from WAX-I when both CE1 and GH10 were present, which might be due to GH10 
releasing soluble oligosaccharides that $\mathrm{CE} 1$ can utilize as substrate. CE1 also displayed activity towards solubilized 5-O-trans-feruloyl- $\alpha$-L-Araf $\left(k_{\text {cat }}=36.35 \mathrm{~s}^{-1}\right)$. This suggests that CE1 preferably acts on soluble oligosaccharides.

Abbreviations: 4NPA, 4-nitrophenyl- $\alpha$-L-arabinofuranoside; 4NPX, 4-nitrophenyl- $\beta$-Dxylopyranoside; ABF, $\alpha$-L-arabinofuranosidase; Araf, $\alpha$-L-1,3-arabinofuronose; AX, arabinoxylan; $\beta$ D-1,4-linked xylopyranose (Xyl $p$ ); carbohydrate esterase family (CE); DNS, 3,5-dinitrosalicylic acid reagent; EPS, exopolysaccharide; FA, ferulic acid; FAE, ferulic acid esterase; GH, glycoside hydrolase family; $T_{\mathrm{m}}$, melting temperature; XOS, xylooligosaccharide; WAX-I, insoluble wheat arabinoxylan

Keywords: arabinofuranosidase; arabinoxylan; multi-enzyme; ferulic acid esterase; xylanase

\section{Introduction}

Arabinoxylan (AX) is the dominant component of the hemicellulose part of lignocellulose from grass cell walls [1], which constitute the feed in many biorefineries [2,3]. AXs consist of a backbone of $\beta$ D-1,4-linked xylopyranose residues (Xylp), single substituted with $\alpha$-L-1,3-arabinofuronose (Araf) and double substituted with $\alpha$-L-1,2- and $\alpha$-L-1,3-Araf, which can be further substituted with 5-O linked hydroxycinnamic acids [4]. Other substituents are also present in some species [1,5]. Complete saccharification of AXs requires several enzymes such as ferulic acid esterases (FAEs) (EC 3.1.1.72), $\alpha$-L-arabinofuranosidases (ABFs) (EC 3.2.1.55) and $\beta$-D-1,4-xylanases (EC 3.2.1.8), which in combination will catalyze production of the monosaccharides or xylooligosaccharides (XOSs) [6,7]. To achieve a synergistic effect the enzymes working together on a particular part of e.g. the 
hemicellulose must be in close proximity. However, the significance of ferulic acid removal has not been considered previously in kinetic assessments.

The present study concerns a multi domain enzyme with three catalytic domains; a carbohydrate esterase family 1 (CE1), a glycoside hydrolase family 62 (GH62) and a GH10. This multi domain enzyme was identified in a metagenomic study of anaerobic digesters [8]. In order to determine the effectiveness of being a multi-enzyme, CE1-GH62-GH10 was also expressed as individual domains (CE1, GH62 and GH10), and without the N- or C-terminal domains (CE1-GH62 and GH62-GH10). These were assayed individually and in combination, which demonstrated that they are a FAE, an ABF and a $\beta$-D-1,4-xylanase, respectively. When combined WAX-I was broken down to monomers, xylobiose, and xylotriose. We hypothesized that CE1-GH62-GH10 would catalyze AX degradation more efficiently than an equimolar combination of the individual domains.

\section{Materials and methods}

\subsection{Sequence analysis}

An open reading frame encoding CE1-GH62-GH10 (GenBank acc. nr. BK010417.1) was identified in a metagenomic study of the anaerobic digester Fredericia (GenBank acc. nr. MTKW00000000.1) on a contig (GenBank acc. nr. MTkW01027953.1, bp 5749-8928) [8]. Domains were mapped with dbCan [9]. CE1-GH62-GH10 was analyzed for the presence of a signal peptide by SignalP 4.1 [10]. Disulfide bonds were predicted by DiANNA 1.1 [11]. MW and pI were predicted by Compute pI [12] and $\mathrm{pI}$ were 5.73, 5.63, 5.64, 6.28, 5.36 and 5.92 for CE1-GH62-GH10, CE1-GH62, GH62-GH10, CE1, GH62 and GH10, respectively, and molecular mass' were 119.1, 78.4, 76.9, 38.7, 36.1 and 39.7 $\mathrm{kDa}$, respectively. The theoretical molar extinction coefficients were calculated using ProtParam (http://web.expasy.org/protparam) was 206290, 137420, 152430, 53860, 83435 and $68870 \mathrm{M}^{-1} \mathrm{~cm}^{-1}$ for CE1-GH62-GH10, CE1-GH62, GH62-GH10, CE1, GH62 and GH10, respectively. BLASTp 
searches were performed against the NCBI non-redundant protein database [13]. PSIPRED (http://bioinf.cs.ucl.ac.uk/psipred/) was used to predict secondary structure elements [14].

\subsection{Genes, cloning, expression and purification}

The codon optimized mature gene (Supplementary Table 1) for Escherichia coli encoding the CE1GH62-GH10 (residues 29-1077) (Fig. 1) and truncations (CE1-GH62 (residues 29-716); GH62GH10 (residues 407-1077); CE1 (residues 29-371); GH62 (residues 407-716) and GH10 (residues 727-1077) were purchased and cloned into pET-22b (CE1-GH62-GH10; CE1-GH62; GH62-GH10 and GH62) or pET-28a (CE1 and GH10) using the restriction sites Nco1 and Xho1 (GenScript, Piscataway, NJ, USA) in frame with the HisTag and in pET-22b in frame with the PelB leader sequence and the HisTag. The resulting plasmids were transformed into E. coli strain BL21 (DE3) (Novagen, Nottingham, United Kingdom). Transformants were grown at $37{ }^{\circ} \mathrm{C}$ in LB medium supplemented with $100 \mu \mathrm{g} \mathrm{ml}^{-1}$ ampicillin (pET-22b) or $50 \mu \mathrm{g} \mathrm{ml}^{-1}$ kanamycin (pET-28a) until cell growth reached $\mathrm{OD}_{600} 0.8$, cooled on ice for $30 \mathrm{~min}$. and expression was induced by addition of 0.1 $\mathrm{mM}$ (final concentration) isopropyl thio- $\beta$-D-galactoside to the LB medium. The cultures were grown at $15{ }^{\circ} \mathrm{C}$ for further $16-18 \mathrm{~h}$. The cells were then pelleted $\left(2000 \mathrm{~g} ; 20 \mathrm{~min} ; 4^{\circ} \mathrm{C}\right)$, resuspended in $1: 10$ volume of $50 \mathrm{mM}$ Tris, $500 \mathrm{mM} \mathrm{NaCl}, 20 \mathrm{mM}$ imidazole, $\mathrm{pH} 7.5$ and lysed by sonication. The lysate was centrifuged $\left(20000 \mathrm{~g} ; 20 \mathrm{~min} ; 4^{\circ} \mathrm{C}\right)$ and the supernatant was filtered $(0.45 \mu \mathrm{m}$ Durapore membrane filters; Millipore, Billerica, MA, USA), applied to a $5 \mathrm{ml}$ HisTrap SP HP column (GE Healthcare Uppsala, Sweden) equilibrated with $50 \mathrm{mM}$ Tris, $500 \mathrm{mM} \mathrm{NaCl}, 20 \mathrm{mM}$ imidazole pH 7.5 and eluted $\left(2 \mathrm{ml} \mathrm{min}^{-1}\right)$ by a linear $20-500 \mathrm{mM}$ imidazole gradient (30 CV). Fractions containing the target enzymes were pooled, concentrated (Viaspin (10 kDa), Sartorius, Goettingen, Germany) and applied to a Hiload 16/60 Superdex G200 column (GE Healthcare, Uppsala, Sweden) equilibrated with $10 \mathrm{mM} \mathrm{NaOAc}, 150 \mathrm{mM} \mathrm{NaCl}$, pH $6\left(0.5 \mathrm{ml} \mathrm{min}^{-1}\right)$. Fractions containing pure target enzymes 
were concentrated (Viaspin, $10 \mathrm{kDa}$, Sartorius, Goettingen, Germany) and stored at $4{ }^{\circ} \mathrm{C}$. For CE1GH62, fractions containing CE1-GH62 were pooled, dialyzed (SnakeSkin, 3.5 kDa, Thermo Scientific, Rockford, IL, USA) into $10 \mathrm{mM} \mathrm{NaOAc,} \mathrm{pH} 6$ and applied to a $1 \mathrm{ml}$ ResourceQ column (GE Healthcare, Uppsala, Sweden) equilibrated with $10 \mathrm{mM} \mathrm{NaOAc}$, pH $6\left(1 \mathrm{ml} \mathrm{min} \mathrm{m}^{-1}\right)$ and eluted by a linear $0-500 \mathrm{mM} \mathrm{NaCl}$ gradient $(30 \mathrm{CV}$ ). Fractions containing pure CE1-GH62 were pooled, concentrated as above and stored at $4{ }^{\circ} \mathrm{C}$. All chromatographic steps were carried out at $8{ }^{\circ} \mathrm{C}$. The purity was checked on $12 \%$ SDS-PAGE gels. The concentration of the protein samples were measured by $\mathrm{A}_{280}$ using the theoretically obtained molar extinction coefficients.

\subsection{Enzyme activity assays}

pH and temperature optima and stability: $40 \mu 1$ 1\% insoluble wheat arabinoxylan (WAX-I) (Megazyme, Wicklow, Ireland) suspended in $40 \mathrm{mM}$ Britton-Robinson universal buffers $\mathrm{pH} 2-11$ [15], 0.005\% Triton-X100 were mixed with $10 \mu \mathrm{l}(3-10 \mu \mathrm{M})$ CE1-GH62-GH10, GH62 or GH10 and incubated for $1 \mathrm{~h}$ with agitation at $37^{\circ} \mathrm{C}$ after $2 \mathrm{~min}$ preincubation at $37^{\circ} \mathrm{C}$ in triplicates. The reactions were stopped by adding $75 \mu 1$ 3,5-dinitrosalicylic acid reagent (DNS), incubated at $95^{\circ} \mathrm{C}$ for $15 \mathrm{~min}$, cooled on ice for $15 \mathrm{~min}$, centrifuged at $20000 \mathrm{~g}$ for $5 \mathrm{~min}$ at $4{ }^{\circ} \mathrm{C}$ and quantifying reducing sugars by measuring $\mathrm{A}_{540}$ at $100 \mu \mathrm{l}$ [16] using xylose as standard (0.16-10 mM). One activity unit (U) was defined as the amount of enzyme releasing $1 \mu \mathrm{mol} \mathrm{min}{ }^{-1}$ xylose and/or arabinose.

The $\mathrm{pH}$ optimum for $\mathrm{CE} 1$ were determined in duplicates by mixing $2 \mu \mathrm{l} 0.01 \mu \mathrm{M}$ CE1 with $8 \mu 15$ $\mathrm{mM}$ 5-O-trans-feruloyl- $\alpha$-L-Araf dissolved in $40 \mathrm{mM}$ Britton-Robinson universal buffers $\mathrm{pH} 2-11$ [15] and incubated for $9 \mathrm{~min}$ at $37^{\circ} \mathrm{C}$ after $2 \mathrm{~min}$ preincubation at $37^{\circ} \mathrm{C}$. Quantification of the released ferulic acid (FA) was performed as described below.

The temperature optima for CE1-GH62-GH10, GH62 and GH10 was determined as above in triplicates except that WAX-I was dissolved in $50 \mathrm{mM} \mathrm{NaOAc}, 0.005 \%$ Triton-X100 pH 6. The 
temperature optimum of CE1 was determined as above in duplicates except 5-O-trans-feruloyl- $\alpha$-LAraf was dissolved in $10 \mathrm{mM} \mathrm{NaOAc}$ pH 6.

The temperature stability for CE1-GH62-GH10, CE1, GH62 and GH10 was determined by incubating the enzymes at $37{ }^{\circ} \mathrm{C}$ and sampled on regular basis. The residual activity for CE1-GH62GH10, GH62 and GH10 were followed and quantified as above in triplicates with WAX-I dissolved in $50 \mathrm{mM}$ NaOAc, $0.005 \%$ Triton-X100 pH 6. CE1s residual activity were followed and determined as above in single experiments with 5-O-trans-feruloyl- $\alpha$-L-Araf dissolved in $10 \mathrm{NaOAc}$ pH 6.

Nano differential scanning fluorimetry was used to analyze the conformational stability of CE1GH62-GH10, CE1, GH62 and GH10 using a Prometheus NT48 (Nanotemper, Munich, Germany) by determining their melting temperatures $\left(T_{\mathrm{m}}\right)$. The capillaries were filled with $10 \mu$ protein sample in $10 \mathrm{mM}$ NaOAc pH $6\left(0.1-0.55 \mathrm{mg} \mathrm{ml}^{-1}\right)$ and placed on the sample holder. A temperature gradient of $3.3{ }^{\circ} \mathrm{C} \cdot \mathrm{min}^{-1}$ from 20 to $95{ }^{\circ} \mathrm{C}$ was applied and the intrinsic protein fluorescence at 330 and $350 \mathrm{~nm}$ was recorded.

Hydrolysis of wheat AX: Specific activities were determined in triplicates by mixing $40 \mu 11 \% \mathrm{WAX}$ I suspended in $50 \mathrm{mM}$ NaOAc, $0.005 \%$ Triton-X100 pH6 with $10 \mu \mathrm{l}(3-15.8 \mu \mathrm{M}) \mathrm{CE} 1-\mathrm{GH} 62-\mathrm{GH} 10$ and all truncations except CE1 and incubated for $10 \mathrm{~min}$ with agitation at $37{ }^{\circ} \mathrm{C}$ after 2 min preincubation at $37^{\circ} \mathrm{C}$. The reactions were stopped and quantified using DNS as above.

Kinetic parameters were determined in triplicates from initial rates by following total sugar release from WAX-I for CE1-GH62-GH10 and all truncations except CE1. Reactions were initiated by adding $80 \mu \mathrm{l}$ enzyme (3-10 $\mu \mathrm{M})$ to $320 \mu \mathrm{l}$ WAX-I (5-35 $\left.\mathrm{mg} \mathrm{ml}^{-1}\right)$ after two min preincubation at 37 ${ }^{\circ} \mathrm{C}$. Aliquots $(50 \mu \mathrm{l})$ were removed every $5 \mathrm{~min}$ during $15 \mathrm{~min}$. and stopped and quantified with DNS as above.

$K_{\mathrm{m}}$ and $k_{\text {cat }}$ were obtained by fitting the classical Michaelis-Menten equation $v_{o}=V_{\max } /\left(1+\left(K_{\mathrm{m}} /\left[\mathrm{S}_{0}\right]\right)\right.$ using SigmaPlot 13.0 (SYSTAT Software, San Jose, CA, USA). $v_{o}$ is the initial reaction rate, $v_{\max }$ 
maximum rate, and $\left[\mathrm{S}_{0}\right]$ substrate concentration. Where $k_{\mathrm{cat}} / K_{\mathrm{m}}$ alone is reported this was determined by monitoring the initial rate at a range of substrate concentrations significantly below the $K_{\mathrm{m}}$ such that a linear plot of $v_{o}$ vs. [ $\left.\mathrm{S}_{0}\right]$ was obtained. Thus, the initial rate of substrate hydrolysis gives a direct readout of $k_{\mathrm{cat}} / K_{\mathrm{m}}$ using the equation $k_{\mathrm{cat}} / K_{\mathrm{m}}=v_{o} /\left[\mathrm{S}_{0}\right]^{*}[\mathrm{E}] .[\mathrm{E}]$ is enzyme concentration.

The hydrolysis products were determined in duplicates for CE1-GH62-GH10 and all truncations by mixing $40 \mu \mathrm{l}$ enzyme $(3-10 \mu \mathrm{M})$ with $160 \mu 110 \mathrm{mg} \mathrm{ml}^{-1}$ WAX-I and allowing the reaction to proceed for $16 \mathrm{~h}$ at $20{ }^{\circ} \mathrm{C}$. The reaction mixtures were centrifuged at $10000 \mathrm{~g}$ for $5 \mathrm{~min}$ at $4{ }^{\circ} \mathrm{C}$ after $16 \mathrm{~h}$ and the reactions were stopped by passing the reaction mixture over a membrane (Viaspin, $3 \mathrm{kDa}$, Sartorius, Goettingen, Germany). The released mono- and oligosaccharides were analyzed by highperformance anion exchange chromatography with pulsed amperometric detection (HPAEC-PAD). The analysis' was carried out on a Dionex ICS3000 system equipped with a CarboPac ${ }^{\mathrm{TM}}$ PA1 (4mm x $250 \mathrm{~mm}$ ) analytical column and a CarboPac ${ }^{\mathrm{TM}}$ PA1 $(4 \mathrm{~mm}$ x $50 \mathrm{~mm}$ ) guard column (all Dionex Corp., Sunnyvale, CA, USA) at a flow rate of $1 \mathrm{ml} \mathrm{min}^{-1}$ at $25^{\circ} \mathrm{C}$. The eluent system comprised MilliQ water (A), $\mathrm{NaOH}(\mathrm{B})$, and $\mathrm{NaOAc}$ with $0.02 \%$ (w/v) $\mathrm{NaN}_{3}(\mathrm{C})$. Elution profile is given in $\mathrm{mM}$ B:C. Elution was performed isocratic at 50:0 for $15 \mathrm{~min}$, linear gradient to 75:0 in 5 min, linear gradient to 100:50 in $5 \mathrm{~min}$, isocratic at 100:50 for $25 \mathrm{~min}$, followed by column wash at 100:300 for $5 \mathrm{~min}$ and reequilibration of the column at 50:0 for $15 \mathrm{~min}$. External standards of Araf, Xylp and XOSs with a degree of polymerization of 2-6 were applied for quantification. The release of FA was quantified by reverse phase HPLC and UV detection using trans-FA as external standard previously described [17].

Hydrolysis of 4-nitrophenyl glycosides: The specific activity for GH10 and GH62 towards 4nitrophenyl- $\alpha$-L-arabinofuranoside (4NPA) and 4-nitrophenyl- $\beta$-D-xylopyranoside (4NPX) was determined in triplicates by mixing $20 \mu 110 \mathrm{mM}$ 4-nitrophenyl glycoside dissolved in water with 20 $\mu 1125 \mathrm{mM}$ NaOAc, $0.005 \%$ Triton-X100 pH 6 which after 2 min preincubation at $37{ }^{\circ} \mathrm{C}$ was mixed 
with $10 \mu 120 \mu \mathrm{M}$ GH62 or $10 \mu \mathrm{M}$ GH10. The reaction $\left(10 \mathrm{~min} ; 37^{\circ} \mathrm{C}\right.$ ) was stopped by $1 \mathrm{M} \mathrm{Na}_{2} \mathrm{CO}_{3}$ $(100 \mu \mathrm{l})$ and $4 \mathrm{NP}$ quantified spectrophotometrically at $410 \mathrm{~nm}$ using $4 \mathrm{NP}(0-0.5 \mathrm{mM})$ as standard.

One U was defined as the amount of enzyme releasing $1 \mu \mathrm{mol} \mathrm{min}^{-1} 4 \mathrm{NP}$. Similarly, CE1's activity towards 4-nitrophenyl butyrate by diluting the dimethyl sulfoxide solubilized 4-nitrophenyl butyrate in water to a concentration at $10 \mathrm{mM}$.

GH62 regioselectivity: Specific activity of GH62 was determined in triplicates for $\mathrm{A}^{2+3} \mathrm{XX}$ [ $\alpha$-L-Araf$(1 \rightarrow 2)]$-[ $\alpha-\mathrm{L}-\mathrm{Ara} f-(1 \rightarrow 3)]-\beta-\mathrm{D}-\mathrm{Xyl} p-(1 \rightarrow 4)-\beta-\mathrm{D}-\mathrm{Xyl} p-(1 \rightarrow 4)-\beta-\mathrm{D}-\mathrm{Xylp}], \quad \mathrm{XA}^{2+3} \mathrm{XX} \quad[\beta-\mathrm{D}-\mathrm{Xyl} p-$ $(1 \rightarrow 4)$ - $[\alpha-L-A r a f-(1 \rightarrow 2)]-[\alpha-L-A r a f-(1 \rightarrow 3)]-\beta$-D-Xylp-( $1 \rightarrow 4)-\beta$-D-Xylp-( $1 \rightarrow 4)-\beta$-D-Xylp], A ${ }^{3} X[\alpha-$

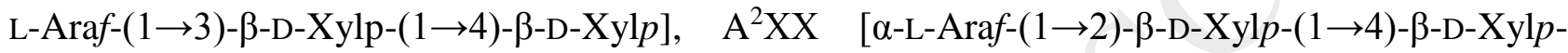
$(1 \rightarrow 4)-\beta-\mathrm{D}-\mathrm{Xyl} p]$ and a mixture of $\mathrm{XA}^{3} \mathrm{XX}[\beta-\mathrm{D}-\mathrm{Xyl} p-(\alpha-\mathrm{L}-\mathrm{Ara} f-(1 \rightarrow 3)-\beta-\mathrm{D}-\mathrm{Xyl} p-(1 \rightarrow 4)-\beta-\mathrm{D}-\mathrm{Xyl} p-$ $(1 \rightarrow 4)-\beta$-D-Xyl $p(50 \%)$ and $\mathrm{XA}^{2} \mathrm{XX} \quad[\beta$-D-Xylp-( $1 \rightarrow 4)-[\alpha-\mathrm{L}-\operatorname{Ara} f-(1 \rightarrow 2)]-\beta$-D-Xyl $p-(1 \rightarrow 4)-\beta$-DXylp] (50\%) (all Megazyme, Wicklow, Ireland), dissolved in 50 mM NaOAc, $0.005 \%$ Triton-X100 pH 6 by mixing $20 \mu \mathrm{l} 9.8 \mu \mathrm{M}$ GH62 with $80 \mu \mathrm{l} 5 \mathrm{mM}$ arabinoxylooligosaccharide (AXOS) and incubated for $10 \mathrm{~min}$ at $37{ }^{\circ} \mathrm{C}$ after 2 min preincubation at $37{ }^{\circ} \mathrm{C}$. The reactions were stopped by adding $100 \mu \mathrm{l} 1 \mathrm{M}$ trichloroacetic acid and the released Araf was quantified using the Lactose/Galactose Assay Kit (Rapid) (Megazyme, Wicklow, Ireland). One U was defined as the amount of enzyme releasing $1 \mu \mathrm{mol} \min ^{-1}$ Araf.

Hydrolysis of 5-O-trans-feruloyl- $\alpha$-L-Araf: The substrate methyl 5-O-trans-feruloyl- $\alpha$-L-Araf was synthesized from L-(+)-arabinose and trans-FA (both Sigma-Aldrich, St. Louis, MI, USA), essentially as described by Hatfield et al. [18]. In brief, a mixture of methyl glucosides were produced from L-(+)-arabinose by Fischer glycosylation. To allow separation, the mixture is per- $O$ benzoylated, followed by selective crystallization of methyl 2,3,5-tri- $O$-benzoyl- $\alpha$-L-Araf. Benzoyl protecting groups were removed under Zemplén conditions. Whereas Hatfield describes workup by neutralization with Amberlite ion-exchange resin [18], we employed an alternative procedure 
described by Lopez et al. [19]. The trans-FA was then acetylated on the phenolic hydroxyl, converted to the acid chloride, and coupled to the methyl $\alpha$-L-Araf in pyridine. The coupling is fairly selective for the 5-position. The acetyl protection group on the trans-FA was finally removed selectively with 10 eq. pyrrolidine in dichloromethane to yield the target product. NMR data were in accordance with those reported by Hatfield et al. [18]. ESI-MS showed 341.12 [M+H]+.

Specific activity for CE1 was determined in duplicates by mixing $20 \mu 10.01 \mu \mathrm{M}$ CE1 with $80 \mu 15$ mM 5-O-trans-feruloyl- $\alpha$-L-Araf dissolved in $10 \mathrm{mM} \mathrm{NaOAc} \mathrm{pH} 6$ and incubated for 9 min at $37^{\circ} \mathrm{C}$ after 2 min preincubation at $37{ }^{\circ} \mathrm{C}$. Quantification of the released FA was performed by liquid chromatography electrospray ionization mass spectrometry (LC-ESI-MS) on an Amazon SL iontrap (Bruker Daltonics, Bremen Germany) coupled to an UltiMate 3000 UHPLC (Dionex corp. Sunnyvale, CA USA) equipped with a Hypersil GOLD column $(150 \mathrm{~mm} \times 2.1 \mathrm{~mm} ; 3 \mu \mathrm{m}$, Thermo Fisher Scientific. Waltham, MA, USA). The chromatography was performed at $0.4 \mathrm{ml} \mathrm{min}^{-1}$ at $40{ }^{\circ} \mathrm{C}$. The eluent system comprised a two-eluent system with milliQ water (A) and acetonitrile (B). In addition, $0.01 \%$ formic acid was present at all time. The elution profile is given in $\% \mathrm{~B}$. Linear gradient from $20-90 \%$ B in $0.5 \mathrm{~min}$, isocratic $90 \%$ B for $2 \mathrm{~min}$, followed by re-equilibration at $20 \%$ B for 3.5 min. The electrospray was operated in negative mode with UltraScan mode and a scan range from $100-1000 \mathrm{~m} / \mathrm{z}$, smart parameter setting of $190 \mathrm{~m} / \mathrm{z}$, capillary voltage at $4.5 \mathrm{kV}$, end plate off-set 0.5 $\mathrm{kV}$, nebulizer pressure at $3.0 \mathrm{bar}$, dry gas flow at $12.0 \mathrm{~L} \mathrm{~min}^{-1}$, and dry gas temperature at $280{ }^{\circ} \mathrm{C}$. CID fragmentation of deprotonated ions was performed by Multiple Reaction Monitoring using SmartFrag enhanced amplitude ramping from 80 to $120 \%$, fragmentation time $20 \mathrm{~ms}$. Quantification was performed in Compass QuantAnalysis 2.2 (Bruker Daltonics, Bremen Germany) using trans-FA as external standard. One $U$ was defined as the amount of enzyme releasing $1 \mu \mathrm{mol} \mathrm{min}{ }^{-1} \mathrm{FA}$.

Kinetic parameters for CE1 was determined from initial rates by following the release of FA. Reactions were initiated by adding $20 \mu 10.01 \mu \mathrm{M}$ CE1 to $80 \mu 1$ 5-O-trans-feruloyl- $\alpha$-L-Araf $(0.05-4$ 
$\mathrm{mM})$ after $2 \mathrm{~min}$ preincubation at $37^{\circ} \mathrm{C}$. Aliquots $(2 \mu \mathrm{l})$ were removed during $16.5 \mathrm{~min}$. and quantified as above. $K_{\mathrm{m}}$ and $k_{\mathrm{cat}}$ were obtained were obtained as above.

Binding assay: Adsorption assays were performed to investigate binding of the individual catalytic domains to WAX-I. WAX-I was washed two times in $50 \mathrm{mM} \mathrm{NaOAc} \mathrm{pH}$ 6. Then $5 \mu \mathrm{CE} 1(4 \mu \mathrm{M})$, GH62 $(4 \mu \mathrm{M})$ or GH10 $(6 \mu \mathrm{M})$ and $95 \mu \mathrm{WAX}-\mathrm{I}\left(0.078-20 \mathrm{mg} \mathrm{ml}^{-1}\right)$ in $50 \mathrm{mM} \mathrm{NaOAc} \mathrm{pH} 6$ and $0.005 \%(\mathrm{w} / \mathrm{v}) \mathrm{BSA}$ were incubated in triplicates at $4{ }^{\circ} \mathrm{C}$ for $30 \mathrm{~min}$ and centrifuged $(20000 \mathrm{~g}$ and 4 ${ }^{\circ} \mathrm{C}$ for $10 \mathrm{~min}$ ). Protein concentrations in the supernatants were determined from $\mathrm{A}_{280}$ readings. The $K_{\mathrm{d}}$ was obtained by fitting the Langmuir adsorption isotherm to the amount of bound enzyme, $\mathrm{B}=$ $\frac{\mathrm{B}_{\max }[\mathrm{S}]}{K_{\mathrm{D}}[\mathrm{S}]}$, where $\mathrm{B}$ being the bound enzyme amount, $[\mathrm{S}]$ the WAX-I concentration, and $\mathrm{B}_{\max }$ the maximum adsorption capacity.

Hydrolysis of complex substrates: Hydrolysis of hydrothermally pretreated biomass was performed to test the performance of CE1-GH62-GH10 enzyme versus the combined mixture of each individual enzyme $\mathrm{CE} 1+\mathrm{GH} 62+\mathrm{GH} 10$ on substrates used in industrial processing of lignocellulosic biomass to produce platform sugars. Corn stover, Miscanthus $\times$ giganteus and wheat straw were hydrothermally pretreated $\left(190{ }^{\circ} \mathrm{C}, 10 \mathrm{~min}\right)$. The details of the biomass feedstocks, hydrothermal pretreatment and the preparation of the substrates for hydrolysis experiments have been described previously [20]. Enzymatic hydrolysis treatments were performed in triplicates at 1\% dry mass (DM) substrate loading in $50 \mathrm{mM}$ phosphate buffer $\mathrm{pH} 6$ at $40^{\circ} \mathrm{C}$. Enzyme loading was $10 \mathrm{nmol} \mathrm{g}{ }^{-1} \mathrm{DM}$. The corresponding loading based on protein content was $1.19 \mathrm{mg} \mathrm{g}^{-1} \mathrm{DM}$ for the CE1-GH62-GH10 enzyme, $0.24 \mathrm{mg} \mathrm{g}^{-}$ ${ }^{1} \mathrm{DM}$ for CE1, $0.36 \mathrm{mg} \mathrm{g}^{-1} \mathrm{DM}$ for GH62 and $0.40 \mathrm{mg} \mathrm{g}^{-1} \mathrm{DM}$ for GH10. The hydrothermally pretreated biomass and enzymes were mixed, incubated at $40{ }^{\circ} \mathrm{C}$ during agitation. After $72 \mathrm{~h}$, the reaction was stopped by boiling for $10 \mathrm{~min}$ followed by centrifugation. The supernatants were assayed for reducing sugars using PAHBAH [21] to measure hydrolysis products and corresponding yield with glucose $(0-3 \mathrm{mM})$ as standard. 


\section{Results and Discussion}

\subsection{Sequence analysis}

A 28 residue signal peptide was predicted suggesting that CE1-GH62-GH10 is secreted into the extracellular medium by its bacterial host. This is also to be expected of an enzyme presumably acting on polymeric AX substrates. The domain analysis using dbCAN suggested that the CE1 domain ranged from residue 153 to 366, GH62 from 407 to 683 and GH10 from 736 to 1071 . However, a comparison with other known domains showed that the CE1 properly range from residue 152 to 370 , GH62 from 406 to 716 and GH10 from 726 to 1079 (Fig. 1). The secondary structure prediction showed that e.g. residue 736 is part of an $\alpha$-helix though (Supplementary Fig. 1), which suggests that the N-terminal of GH10 is further upstream. This interpretation is further supported by the secondary structure prediction showing that the regions in between the manually annotated domains do not contain $\beta$-sheets or $\alpha$-helixes (Supplementary Fig. 1), which is consistent with them being linkers. The first 123 residues following the signal peptide is predicted to consist of five $\beta$-strands and loop regions (Supplementary Fig. 1), which is a typical size for carbohydrate binding domains (CBMs) [22]. The secondary structure prediction indicate that the last $\beta$-strand of this putative CBM includes residues 144 to 150 suggesting no linker exist between the putative CBM and CE1. These findings suggest that CE1 and the putative CBM may act in consort and when expressed separately the two domains precipitated during purification (data not shown).

No other enzyme with a domain organization similar to CE1-GH62-GH10 was found with the BLASTp search. This suggests that CE1-GH62-GH10 is unique and novel. Further, the individual domains were not identical to other known enzymes: CE1 showed the highest identity (67\%) to a protein from an Ignavibacteria bacterium (GenBank acc. nr. OGU13894.1); GH62 showed the highest identity (83\%) to a protein from a Planctomycetes bacterium (GenBank acc. nr. 
OHB64507.1); and GH10 showed the highest identity (71\%) to a protein also from a Planctomycetes bacterium (GenBank acc. nr. OHB57576.1). Two disulfide bonds $\left(\mathrm{Cys}^{292}-\mathrm{Cys}^{461}\right.$ and $\mathrm{Cys}^{522}$ Cys $^{775}$ ) were predicted for CE1-GH62-GH10, both located in the GH62 domain. The molecular weight of CE1-GH62-GH10 was calculated to 119138.7 Dalton, which corresponds with the migration in the SDS-PAGE gel (Supplementary Fig. 2).

\subsection{General biochemical properties}

The influence of $\mathrm{pH}$ from 2-11 on CE1-GH62-GH10 activity was observed, which showed that the highest activity was detected at $\mathrm{pH} 4$ and that only at $\mathrm{pH} 2$ no activity could be detected (Fig. 2A). The level of activity was comparable for $\mathrm{pH} 3,6$ and 9 to 11 , while at 5,7 and 8 the activity was notably lower. The observed activity at acidic pH's is most likely dominated by the GH10 activity, which showed a broad $\mathrm{pH}$ optimum ranging from 3-8 when tested on WAX-I. Further, GH10 maintained $\sim 80 \%$ residual activity at 9 and 10 , while at $\mathrm{pH} 3$ and 11 the residual activity was $\sim 65 \%$ (Fig. 2A). GH62 showed a pH optimum ranging from 7-9 when tested on WAX-I and the activity decreased rapidly under acidic conditions (Fig. 2A). CE1-GH62-GH10 and GH10 could thus be used various industrial process, while GH62's use is limited to industrial process under alkaline conditions. Spontaneous hydrolysis of 5-O-trans-feruloyl- $\alpha$-L-Araf increase with $\mathrm{pH}$ and at $\mathrm{pH} 11$ the nonenzyme catalyzed sample (blank) had a 20 times higher level of FA than at pH 2, while at $\mathrm{pH} 9$ and 10 the FA content was about three times higher (data not shown). CE1 displayed the significantly higher activity at $\mathrm{pH} 10$ and 11 and gradually lost residual activity with the drop in $\mathrm{pH}$ until $\mathrm{pH} 2$ where no activity was detected (Fig. 2A). The alkale labile 5-O-trans-feruloyl- $\alpha$-L-Araf bond prompted us to analyze CE1's activity at pH 6 like CE1-GH62-GH10 and the remaining truncations. 
The temperature optima for CE1-GH62-GH10, GH62 and GH10 were $45{ }^{\circ} \mathrm{C}$, while for CE1 it was $35{ }^{\circ} \mathrm{C}$ (Fig. 2B). This resonates well with CE1-GH62-GH10 was isolated from a mesophilic environment.

CE1-GH62-GH10 and the structural integrity of the individual domains was investigated by nano differential scanning fluorimetry. CE1-GH62-GH10 displayed a melting temperature $\left(T_{\mathrm{m}}\right)$ at $71.0 \pm$ $0.05{ }^{\circ} \mathrm{C}$ (Supplementary Fig. 3) suggesting that the three catalytic domains and the CBM unfolds at the same time. CE1, GH62 and GH10 displayed $T_{\mathrm{m}}$ at $69.9 \pm 0.02,65.7 \pm 0.06$ and $71 \pm 0.05{ }^{\circ} \mathrm{C}$, respectively. The difference in $T_{\mathrm{m}}$ for GH62 indicates that in particular GH62 appears to be stabilized by the surrounding domains.

The thermostability of CE1-GH62-GH10, GH62 and GH10 is comparable (Fig. 3); however, CE1 lost half the activity within $145 \mathrm{~min}$ (Fig. 3) at $37^{\circ} \mathrm{C}$, which is surprising as the CE1 $T_{\mathrm{m}}$ was very close to that of CE1-GH62-GH10.

\subsection{The individual domains enzymatic capabilities and substrate affinities}

When examined individually as monomeric enzymes, all three catalytic domains catalyzed the hydrolysis of the bonds expected of enzymes from the respective enzyme families. GH62 catalyzed release of Araf from WAX-I with a reasonable $k_{\text {cat }}\left(1.5 \pm 0.3 \mathrm{~s}^{-1}\right)$ (Table 1 ; Fig. 4A) compared to most other GH62s, and in agreement with all other characterized GH62s [23]. GH62 catalyzed hydrolysis of $\alpha$-L-1,2- and $\alpha$-L-1,3-Araf from single substituted Xylp (with three times higher activity on $\alpha$-L1,2 than on $\alpha$-L-1,3-Araf), but was, as expected, unable to catalyze the hydrolysis of Araf at doubly substituted Xylp (Table 2). GH62 also released Araf from WAX-I (Fig. 5A), however, surprisingly xylobiose, xylotriose were also detected, albeit at very low levels (Fig. 5A). This suggests that GH62 is capable of hydrolyzing the $\beta$-D-1,4 bonds linking the Xylp backbone. Small amounts of xylotetraose were also detected, which was not detected in the presence of GH10 (Fig 5A). The native 
GH62 from the fungus Cochliobolus carbonum has been reported to release Xylp from xylobiose. Further, the enzyme apparently also catalyzed the hydrolysis of the $\beta$-D-1,4 bonds in the wheat arabinoxylan Xylp backbone resulting in the release of longer oligosaccharides, which however amounted to only $2 \%$ of the ABF activity [24]. GH62 did not hydrolyze 4NPX, but did hydrolyze 4NPA (Table 2), which suggests that the observed hydrolysis of the $\beta$-D-1,4 bond is a result of the prolonged incubation, where chances random and conformational motions of the enzyme increase which may lower enzyme selectivity. Although only detailed structural knowledge of the GH62 enzyme can provide a full explanation, the activity does not appear to be biologically or industrially relevant. Interestingly, Xylp, xylobiose, xylotriose and xylotetraose were not produced by CE1-GH62 (Fig 5A).

GH10 primarily produced Xylp and xylobiose, and to a much lesser extend xyloheptaose and a XOS of unknown length, but likely substituted with Araf(Fig. 5A), which were only produced when GH10 was the sole catalytic domain in the reaction mixture. This is similar to what has been observed for other GH10 endo- $\beta$-D-xylanases [25,26]. GH10 $k_{\text {cat }}$ and $K_{\mathrm{m}}$ for WAX-I could not be determined due to a high $K_{\mathrm{m}}$ (Table 1; Fig. 4B), and did not hydrolyze 4NPX or 4NPA (Table 2).

Surprisingly, CE1 did not release FA during $16 \mathrm{~h}$ incubation with WAX-I at significant amounts (Fig. 5B). This may suggest that CE1 is not active on insoluble substrates or that the truncation incapacitied CE1s ability to act on insoluble substrates. FA was released when CE1 was mixed with GH62, GH10 and GH62-GH10 (Fig. 5B), which suggests that the decrease in thermostability for CE1 is not the reason for the lack of FA release. 5-O-trans-feruloyl- $\alpha$-L-Araf was synthesized, which unlike the many synthetic substrates used to characterize FAEs mimic the natural substrate. This allowed determination of kinetic parameters on a natural soluble substrate, which resulted in $k_{\text {cat }}$ and $K_{\mathrm{m}}$ values at $36.35 \pm 5.15 \mathrm{~s}^{-1}$ and $0.96 \pm 0.04 \mathrm{mM}$, respectively (Fig. 6). CE1 did not display activity on 4nitrophenyl butyrate, which suggests that CE1 does not possess acetylxylan esterase activity. 
In order to determine the individual domains affinity for WAX-I and obtain an understanding for the underlying reason for the observed $K_{\mathrm{m}}$ values, adsorption assays were performed. These resulted in the following $K_{\mathrm{d}}$ values $0.204 \pm 0.017\left(\mathrm{~B}_{\max }=266 \pm 5\right), 0.099 \pm 0.030\left(\mathrm{~B}_{\max }=116 \pm 7\right)$ and $0.958 \pm$ $0.018 \mathrm{mg} \mathrm{ml}^{-1}\left(\mathrm{~B}_{\max }=308 \pm 14\right)$ for CE1, GH62 and GH10, respectively (Fig. 7). Surprisingly, GH10 displayed the highest $K_{\mathrm{d}}$ for WAX-I. This implies that the enzyme:substrate-complex dissociates relatively fast, while the high $K_{\mathrm{m}}$ implies that the enzyme:substrate-complex forms relatively slowly; this all together shows that GH10 has a low affinity for WAX-I. The low $K_{\mathrm{d}}$ both CE1 and GH62 displayed for WAX-I implies that they dissociate slowly from WAX-I, which may ensure that GH10 despite its low affinity for WAX-I stays within close proximity of its substrate. Similar to GH10, GH62 displayed a high $K_{\mathrm{m}}$ for WAX-I (Table 1; Fig. 4B). This appears also to be the case for CE1 as the $K_{\mathrm{m}}$ for CE1-GH62 is comparable to GH62 (Table 1; Fig. 4A). Hence, CE1, GH62 and GH10 all on individual basis appear to form enzyme:substrate-complex' relatively slowly.

\subsection{Synergistic action and mechanism}

CE1-GH62-GH10 catalyzed the production of FA, Araf, Xylp, xylobiose, and xylotriose when incubated with WAX-I overnight (Fig. 5) demonstrating that CE1-GH62-GH10 is capable of degrading WAX-I. The $k_{\text {cat }}$ and the specificity constant $\left(k_{\text {cat }} / K_{\mathrm{m}}\right)$ was comparable for all the different combinations that included all three catalytic domains when present in equimolar amounts (Table 1: Fig. 4A). This suggests that from a hydrolytic point of view being a multi-enzyme is not an advantage for CE1-GH62-GH10. In Nature where AX is not as easily accessible as when testing the enzyme on a pure AX in excess amounts one could speculate that having all enzymes needed for hydrolysis of AX linked together would be an advantage. However, this proved not to be the case when testing the enzymes on pretreated biomass (Table 3). Measurement of reducing sugars revealed minor degree of hydrolysis of hydrothermally pretreated biomass by CE1-GH62-GH10 enzyme and the individual 
domains in an equimolar mix (Table 3). There was higher release of hydrolysis products in Miscanthus $\times$ giganteus, but no significant difference between CE1-GH62-GH10 and the individual domains in equimolar mix (Table 3). The low degree of hydrolysis indicated that the AX moieties in the pretreated biomass are not readily accessible for the enzymes. Presumably, this was due to presence of lignin, which restricted the access of the enzymes to hemicellulose moieties in the biomass. The surface abundance of lignin in particular was indeed found to be restricting the access of cellulolytic enzymes to these substrates [27]. However, in ADs from where the gene encoding for CE1-GH62-GH10 was isolated, the bacteria have previously been shown to form a dense matrix of exopolysaccharides (EPS) within which enzymes are trapped [28]. This limits the synergistic actions needed when enzymes degrade complex polysaccharides. However, if the enzymes form a multienzyme like CE1-GH62-GH110 this may facilitate the synergistic action in the dense EPS matrix. The kinetic data also shows that when CE1 is linked to GH62 there is a significant decrease in both $k_{\text {cat }}$ and specific activity - i.e. the specific activity for GH62 is fourfold higher than for CE1-GH62 on WAX-I and $k_{\text {cat }}$ is twofold higher (Table 1; Fig. 4A). Further, FA was not detected after CE1 and CE1-GH62 had been incubated for $16 \mathrm{~h}$ with WAX-I in significant amounts (Fig. 5B), however, when GH10 is present FA is released (Fig. 5B). This could be due to that GH10 catalyze the production of soluble oligosaccharides CE1 can act on, which together with the high activity on 5-O-trans-feruloyl$\alpha$-L-Araf, suggests that CE1 is only able to act on soluble substrates. However, GH62 displayed significantly lower activity on soluble AXOS than on WAX-I (Table 1;2), which suggests that GH62 primarily catalyze the hydrolysis of the $\alpha-1,2$ - and $\alpha-1,-3$-linked Araf prior to GH10 hydrolysis of the xylan main chain.

\section{Conclusions}


A gene encoding CE1-GH62-GH10 identified in a metagenome obtained from wastewater treatment surplus sludge includes three distinct catalytic domains classified as a CE1 FAE, GH62 ABF and a GH10 $\beta$-D-1,4-xylanases. In addition, a putative CBM was identified at the $\mathrm{N}$-terminal. Combined these catalytic domains broke WAX-I down to FA, Araf, Xylp, xylobiose and xylotriose. To our surprise, CE1-GH62-GH10 and an equimolar mix of the individual domains displayed similar activities towards WAX-I and insoluble heterogeneous substrates. Hence, on these substrates under laboratory conditions being a multi-enzyme is not an advantage for CE1-GH62-GH10. However, within the dense EPS matrix found in ADs this secure that the domains are kept in close proximity, which will ensure the synergistic effect is not lost due to diffusion. Further, in particular the CE1 and GH62 domain is less stable when assayed as individual domains than CE1-GH62-GH10 suggesting that the enzymes stabilize one another.

\section{Acknowledgements}

Rikke Nørregaard-Sarup, Novozymes A/S is thanked for performing the nano differential scanning fluorimetry experiments.

\section{Author contributions}

LL and CW conceived the study. JH, DTD, JB, KBRMK and CW planned the experiments. BP, JB, JH, DTD and CW carried out the experiments. JH, DTD, KBRMK, ASM and CW analyzed the data. CW wrote the manuscript with input from all co-authors. All authors have approved the final article.

\section{Funding}


The work was supported by the Villum Foundation (grant number VKR022796) and by Innovation Fund Denmark (Case No: 0603-00522B, BioValue SPIRStrategic Platform for Innovation and Research on value added products from biomass. The funders had no role in the design, analysis, write-up or decision to submit for publication.

\section{Conflict of interest}

CW, JH, DTD, BP, ASM, and LL have no conflicts of interest to declare. JB and KBRMK are employees at Novozymes A/S, however, do not have any conflicts of interest. 


\section{References}

[1] H.V. Scheller, P. Ulvskov, Hemicelluloses., Annu. Rev. Plant Biol. 61 (2010) 263-289. doi:10.1146/annurev-arplant-042809-112315.

[2] D.B. Jordan, M.J. Bowman, J.D. Braker, B.S. Dien, R.E. Hector, C.C. Lee, J.A. Mertens, K. Wagschal, Plant cell walls to ethanol., Biochem. J. 442 (2012) 241-252. doi:10.1042/BJ20111922.

[3] L.R. Lynd, X. Liang, M.J. Biddy, A. Allee, H. Cai, T. Foust, M.E. Himmel, M.S. Laser, M. Wang, C.E. Wyman, Cellulosic ethanol: status and innovation, Curr. Opin. Biotechnol. 45 (2017) 202-211. doi:10.1016/j.copbio.2017.03.008.

[4] L. Saulnier, P.E. Sado, G. Branlard, G. Charmet, F. Guillon, Wheat arabinoxylans: Exploiting variation in amount and composition to develop enhanced varieties, J. Cereal Sci. 46 (2007) 261-281. doi:10.1016/j.jcs.2007.06.014.

[5] M.J. Bowman, B.S. Dien, K.E. Vermillion, J.A. Mertens, Isolation and characterization of unhydrolyzed oligosaccharides from switchgrass (Panicum virgatum, L.) xylan after exhaustive enzymatic treatment with commercial enzyme preparations, Carbohydr. Res. 407 (2015) 42-50. doi:10.1016/j.carres.2015.01.018.

[6] S. Lagaert, A. Pollet, C.M. Courtin, G. Volckaert, $\beta$-xylosidases and $\alpha$-Larabinofuranosidases: accessory enzymes for arabinoxylan degradation., Biotechnol. Adv. 32 (2014) 316-332. doi:10.1016/j.biotechadv.2013.11.005.

[7] P. Biely, S. Singh, V. Puchart, Towards enzymatic breakdown of complex plant xylan structures: State of the art, Biotechnol. Adv. 34 (2016) 1260-1274. doi:10.1016/j.biotechadv.2016.09.001.

[8] C. Wilkens, P.K. Busk, B. Pilgaard, W.-J. Zhang, K.L. Nielsen, P.H. Nielsen, L. Lange, Diversity of microbial carbohydrate active enzymes in Danish anaerobic digesters fed with 
wastewater treatment sludge, Biotechnol. Biofuels. 10 (2017) 158. doi:10.1186/s13068-0170840-y.

[9] L. Huang, H. Zhang, P. Wu, S. Entwistle, X. Li, T. Yohe, H. Yi, Z. Yang, Y. Yin, dbCANseq: a database of carbohydrate-active enzyme (CAZyme) sequence and annotation, Nucleic Acids Res. (2017) 1-6. doi:10.1093/nar/gkx894.

[10] T.N. Petersen, S. Brunak, G. von Heijne, H. Nielsen, SignalP 4.0: discriminating signal peptides from transmembrane regions, Nat. Methods. 8 (2011) 785-786. doi:10.1038/nmeth.1701.

[11] F. Ferrè, P. Clote, DiANNA 1.1: An extension of the DiANNA web server for ternary cysteine classification, Nucleic Acids Res. 34 (2006) 182-185. doi:10.1093/nar/gkl189.

[12] E. Gasteiger, C. Hoogland, A. Gattiker, A. Duvaud, M. Wilkins, R.D. Appel, A. Bairoch, Protein identification and analysis tools on the ExPASy server, in: J.M. Walker (Ed.), Proteomics Protoc. Handb., Humana Press, 2005: pp. 571-607.

[13] S.F. Altschul, T.L. Madden, A.A. Schäffer, J. Zhang, Z. Zhang, W. Miller, D.J. Lipman, Gapped BLAST and PSI-BLAST:a new generation of protein database search programs, Nucleic Acids Res. 25 (1997) 3389-3402. doi:10.1093/nar/25.17.3389.

[14] D.W.A. Buchan, F. Minneci, T.C.O. Nugent, K. Bryson, D.T. Jones, Scalable web services for the PSIPRED Protein Analysis Workbench., Nucleic Acids Res. 41 (2013) 349-357. doi:10.1093/nar/gkt381.

[15] H.T.S. Britton, R.A. Robinson, Universal buffer solutions and the dissociation constant of veronal, J. Chem. Soc. (1931) 1456-1462. doi:10.1039/jr9310001456.

[16] A.F. Mohun, I.J. Cook, An improved dinitrosalicylic acid method for determining blood and cerebrospinal fluid sugar levels, J. Clin. Pathol. 15 (1962) 169-180. doi:10.1136/jcp.15.2.169. 
[17] J. Holck, A. Lorentzen, L.K. Vigsnæs, T.R. Licht, J.D. Mikkelsen, A.S. Meyer, Feruloylated and nonferuloylated arabino-oligosaccharides from sugar beet pectin selectively stimulate the growth of bifidobacterium spp. In human fecal in vitro fermentations, J. Agric. Food Chem. 59 (2011) 6511-6519. doi:10.1021/jf200996h.

[18] R.D. Hatfield, R.F. Helm, J. Ralph, Synthesis of methyl 5-O-trans-feruloyl- $\alpha$-Larabinofuranoside and its use as a substrate to assess feruloyl esterase-ectivity, Anal. Biochem. 194 (1991) 25-33. doi:10.1016/0003-2697(91)90146-K.

[19] G. Lopez, C. Nugier-Chauvin, C. Rémond, M. O'Donohue, Investigation of the specificity of an $\alpha$-L-arabinofuranosidase using C-2 and C-5 modified $\alpha$-L-arabinofuranosides, Carbohydr. Res. 342 (2007) 2202-2211. doi:10.1016/j.carres.2007.06.001.

[20] D.T. Djajadi, A.R. Hansen, A. Jensen, L.G. Thygesen, M. Pinelo, A.S. Meyer, H. Jørgensen, Surface properties correlate to the digestibility of hydrothermally pretreated lignocellulosic Poaceae biomass feedstocks, Biotechnol. Biofuels. 10 (2017) 49. doi:10.1186/s13068-0170730-3.

[21] M. Lever, A new reaction for calorimetric determination of carbohydrates, Anal. Biochem. 47 (1972) 273-279. doi:10.1016/0003-2697(72)90301-6.

[22] The CAZypedia Consortium, Ten years of CAZypedia: a living encyclopedia of carbohydrate-active enzymes, Glycobiology. 28 (2018) 3-8. doi:10.1093/glycob/cwx089.

[23] C. Wilkens, S. Andersen, C. Dumon, J.-G. Berrin, B. Svensson, GH62 arabinofuranosidases: Structure, function and applications, Biotechnol. Adv. 35 (2017) 792-804. doi:10.1016/j.biotechadv.2017.06.005.

[24] R.F. Ransom, J.D. Walton, Purification and characterization of extracellular $\beta$-xylosidase and $\alpha$-arabinosidase from the plant pathogenic fungus Cochliobolus carbonum, Carbohydr. Res. 297 (1997) 357-364. doi: 10.1016/S0008-6215(96)00281-9 
[25] J. Linares-Pastén, A. Aronsson, E.N. Karlsson, Structural considerations on the use of endoxylanases for the production of prebiotic xylooligosaccharides from biomass, Curr. Protein Pept. Sci. 19 (2018) 48-67. doi:10.2174/1389203717666160923155209.

[26] G. Pell, L. Szabo, S.J. Charnock, H. Xie, T.M. Gloster, G.J. Davies, H.J. Gilbert, Structural and biochemical analysis of Cellvibrio japonicus xylanase 10C: How variation in substratebinding cleft influences the catalytic profile of family GH-10 xylanases, J. Biol. Chem. 279 (2004) 11777-11788. doi:10.1074/jbc.M311947200.

[27] D.T. Djajadi, M.M. Jensen, M. Oliveira, A. Jensen, L.G. Thygesen, M. Pinelo, M. Glasius, H. Jørgensen, A.S. Meyer, Lignin from hydrothermally pretreated grass biomass retards enzymatic cellulose degradation by acting as a physical barrier rather than by inducing nonproductive adsorption of enzymes Biotechnology for Biofuels, Biotechnol Biofuels. 11 (2018) 1-13. doi:10.1186/s13068-018-1085-0.

[28] B. Frolund, T. Griebe, P. Nielsen, Enzymatic activity in the activated sludge flocmatrix, Appl. Microbiol. Biotechnol. 43 (1995) 755-761.

[29] R. Faure, C.M. Courtin, J.A. Delcour, C. Dumon, C.B. Faulds, G.B. Fincher, S. Fort, S.C. Fry, S. Halila, M.A. Kabel, L. Pouvreau, I.B. Quemener, A. Rivet, H.A. Schols, H. Driguez, M.J. O’Donohue, A brief and informationally rich naming system for oligosaccharide motifs of heteroxylans, Aust. J. Chem. 62 (2009) 533-537. 


\section{Tables}

Table 1: Kinetic parameters for hydrolysis of insoluble wheat arabinoxylan.

\begin{tabular}{ccccc}
\hline & $\begin{array}{c}\text { Specific activity } \\
\left(\mathbf{U} \mathbf{~ m g}^{-1}\right)\end{array}$ & $\begin{array}{c}\boldsymbol{K}_{\mathbf{m}} \\
\left(\mathbf{m g ~ m}^{-\mathbf{1}}\right)\end{array}$ & $\begin{array}{c}\boldsymbol{k}_{\text {cat }} \\
\left(\mathbf{s}^{\mathbf{- 1}}\right)\end{array}$ & $\begin{array}{c}\boldsymbol{k}_{\mathbf{c a t}} / \boldsymbol{K}_{\mathbf{m}} \\
\left(\mathbf{s}^{\mathbf{1}} \mathbf{~ m g}^{-\mathbf{1}} \mathbf{~ m l}\right)\end{array}$ \\
\hline CE1-GH62-GH10 & $1.25 \pm 0.08$ & $42 \pm 9$ & $20.8 \pm 2.6$ & 0.5 \\
\hline CE1-GH62 & $0.20 \pm 0.09$ & $11 \pm 4$ & $0.7 \pm 0.1$ & 0.01 \\
\hline GH62-GH10 & $2.31 \pm 0.09$ & $31 \pm 9$ & $9.3 \pm 1.7$ & 0.3 \\
\hline GH62 & $0.84 \pm 0.12$ & $15 \pm 5$ & $1.5 \pm 0.3$ & 0.1 \\
\hline GH10 & $2.84 \pm 0.28$ & n.d. & n.d. & $0.12 \pm 0.02$ \\
\hline CE1-GH62+GH10 & $0.58 \pm 0.32$ & $38 \pm 16$ & $15.9 \pm 4.3$ & 0.4 \\
\hline CE1+GH62-GH10 & $1.89 \pm 0.50$ & $33 \pm 16$ & $15.1 \pm 4.9$ & 0.5 \\
\hline CE1+GH62+GH10 & $2.61 \pm 0.25$ & $28 \pm 10$ & $17.3 \pm 3.8$ & 0.6 \\
\hline
\end{tabular}

n.d. means no value determined under the described reaction conditions. 
Table 2: Specific activities $\left(\mathrm{U} \mathrm{mg}^{-1}\right)$ for GH62 catalyzed hydrolysis of arabinoxylooligosaccharides (AXOS) and 4-nitrophenyl-glycosides. The one letter code system developed by [29] is used to describe the AXOS.

\begin{tabular}{|c|c|}
\hline $\mathbf{A}^{2+3} \mathbf{X X}$ & n.d. \\
\hline $\mathbf{X} \mathbf{A}^{2+3} \mathbf{X X}$ & n.d. \\
\hline $\mathbf{A}^{\mathbf{3}} \mathbf{X}$ & $0.03 \pm 0.01$ \\
\hline $\mathbf{A}^{2} \mathbf{X X}$ & $0.10 \pm 0.04$ \\
\hline $\mathbf{X A}^{\mathbf{3}} \mathbf{X X :} \mathbf{X A}^{\mathbf{2}} \mathbf{X X}$ & $0.06 \pm 0.02$ \\
\hline 4-nitrophenyl- $\alpha$-L-arabinofuranoside & $0.04 \pm 0.01$ \\
\hline 4-nitrophenyl- $\beta$-D-xylopyranoside & n.d. \\
\hline
\end{tabular}


Table 3: Degree of hydrolysis of total carbohydrate content of steam-pretreated biomass by CE1GH62-GH10 and CE1+GH62+GH10.

CE1-GH62-GH10 (\%) CE1+GH62+GH10 (\%)

\begin{tabular}{ccc}
\hline Corn stover & $1.1 \pm 0.1$ & $1.2 \pm 0.1$ \\
\hline Miscanthus $\times$ giganteus & $2.9 \pm 0.1$ & $2.9 \pm 0.1$ \\
\hline Wheat straw & $1.8 \pm 0.1$ & $1.5 \pm 0.1$ \\
\hline
\end{tabular}




\section{Figure legends}

Fig. 1 Domain architecture of CE1-GH62-GH10.

Fig. 2 A) CE1-GH62-GH10 (•), GH62 (०) GH10 (•) and CE1 (৩) pH optima and B) CE1-GH62-

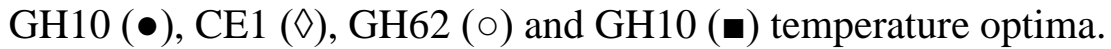

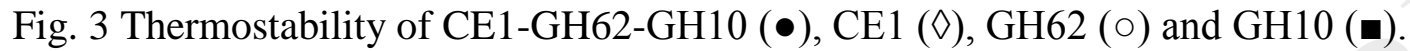

Fig. 4 Insoluble wheat arabinoxylan hydrolysis curves by A) CE1-GH62 (×), GH62-GH10 (»),

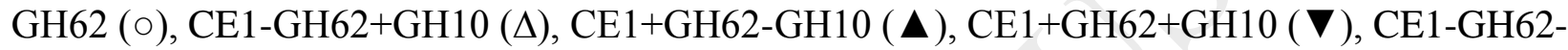
GH10 (•) and B) GH10 (•).

Fig. 5 A) Saccharide products formed after $16 \mathrm{~h}$ enzyme incubation with insoluble wheat arabinoxylan. Degree of polymerization 7 refers to a xylooligosaccharide most likely substituted with arabinofuranose. B) free trans and cis ferulic acid and ferulic acid bound to saccharide products formed after $16 \mathrm{~h}$ enzyme incubation with insoluble wheat arabinoxylan.

Fig. 6 5-O-trans-feruloyl- $\alpha$-L-Araf hydrolysis curve for CE1 $(\diamond)$

Fig. 7 Adsorption analysis of insoluble wheat arabinoxylan binding to CE1 $(\diamond)$, GH62 (०) and GH10 (ם). 

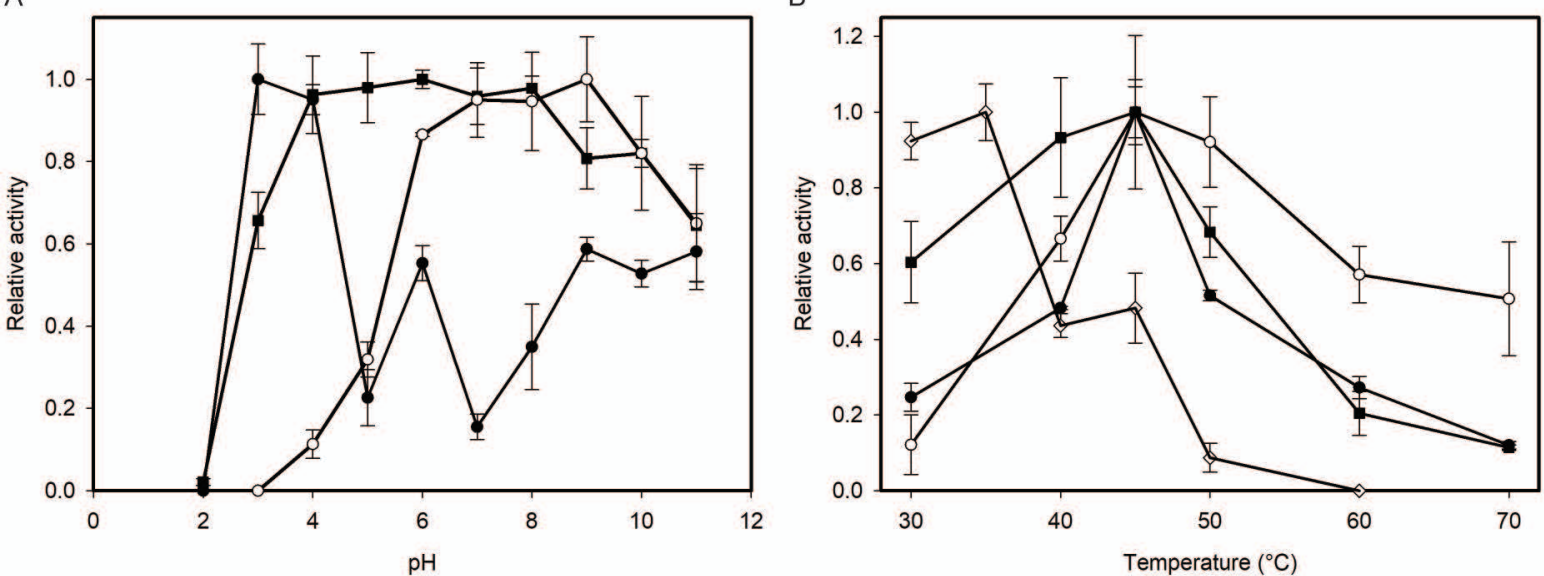


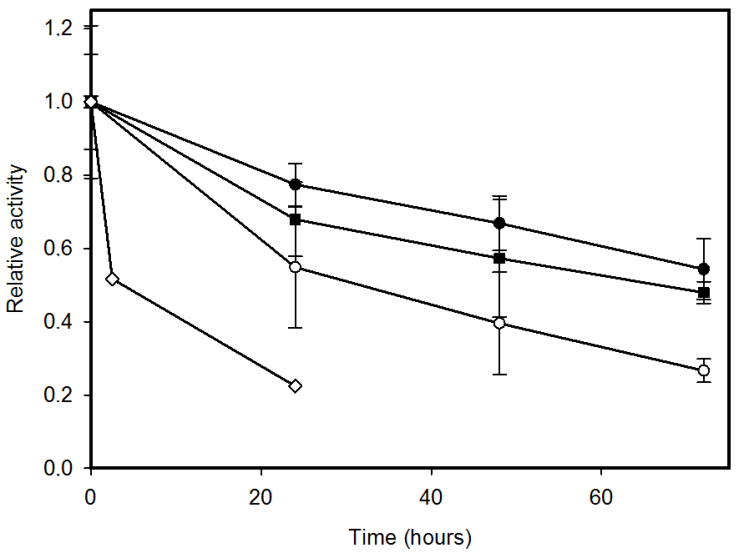




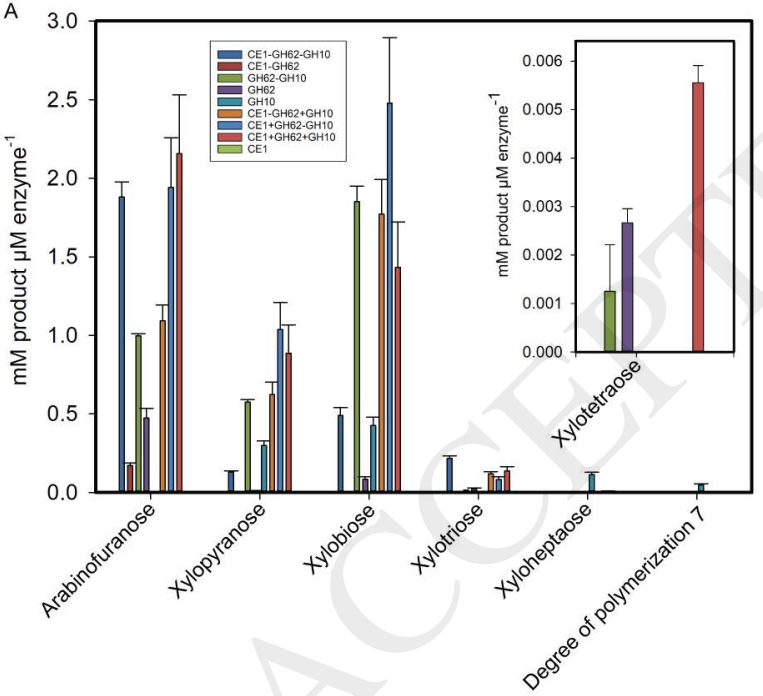

B

$B$

25

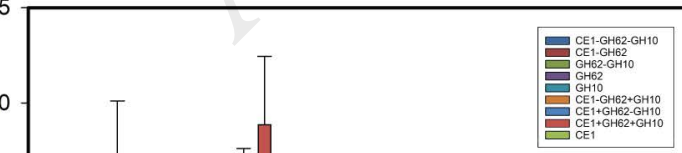

0

5
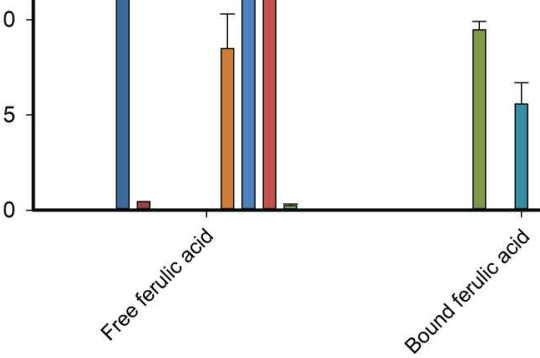


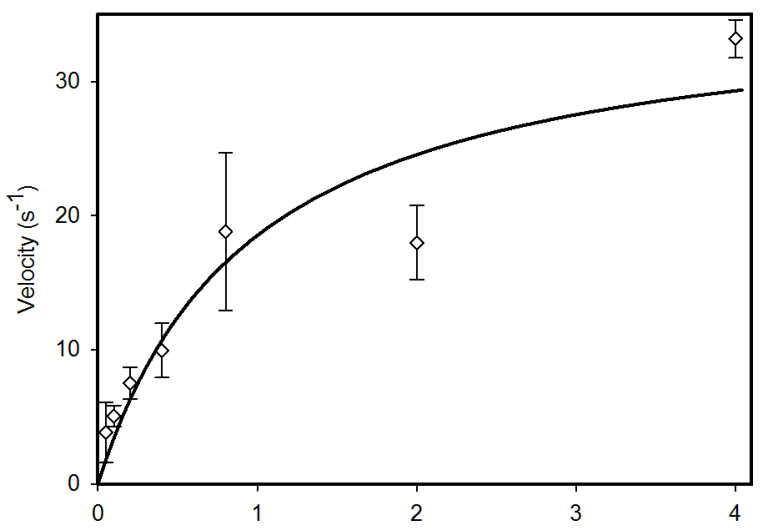

Ferulic acid (mM) 


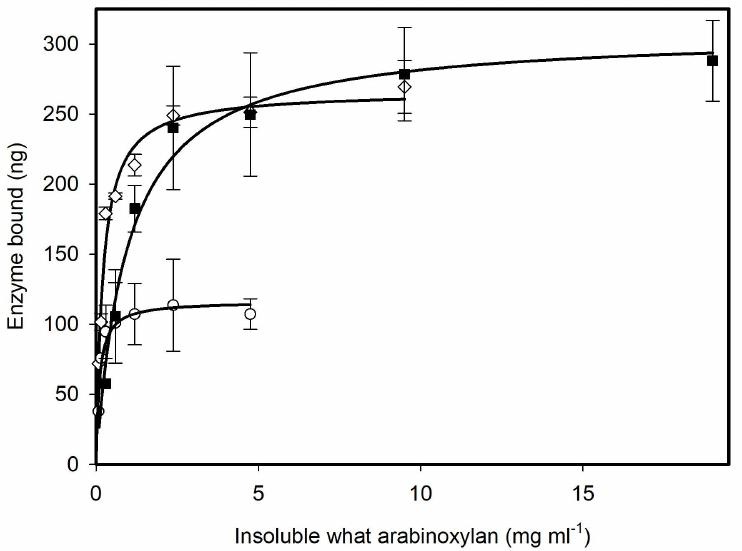

